Just UnDo It: Men Faculty Addressing Gender Inequities in Academia

\begin{abstract}
This study examines the Advocates \& Allies Program, a men faculty peer-to-peer professional development program designed to disrupt gender inequities in academia. The pedagogical approach is grounded in a grassroots-based critical analysis, was developed at a public land grant university, and has been introduced at over twenty additional higher education institutions. Data from five universities and two professional association conferences are included in this study. Results of this mixed methods case analysis illustrate why academic men may be motivated to engage in gender equity work; findings also confirm that the program increases participants' knowledge of unconscious bias and its impacts, prepares men with tools to enact change, and enhances personal commitment to gender equity, thereby affirming and extending the existing knowledgebase on effective allyship. The data suggest that the approach is an effective transformative model of intellectual activism that could be adopted by a wider sphere of academic institutions.
\end{abstract}

Keywords: allyship, university campus climate, gender equity, transformative education 


\section{Just UnDo It: Men Faculty Addressing Gender Inequities in Academia}

It is well-established that gender inequities continue to impact institutions of higher education and other organizational workplaces (Acker, 2012; Barker et al., 2010; Greider et al., 2019; Stamarski \& Son Hing, 2015) and that gender discrimination is a global economic and social justice concern (Kamrany \& Robinson, 2012; Leopold, Ratcheva, \& Zahidi, 2016). In this article the demographic of gender is intentionally constrained to the binary: people who identify as women and people who identify as men. Simultaneously we acknowledge that a more thorough and accurate understanding of gender includes lived experiences that do not conform to this binary conceptualization (Dockendorff \& Geist, 2018; McKenzie, 2014; Messerschmidt, 2012; Pitcher, 2017; Preves, 2005; Shields \& Dicicco, 2011; Wing, 2008; Zamani-Gallaher, Choudhuri, \& Taylor, 2020). Yet, the woman/man binary does importantly reveal the harmful and enduring social realities that yield unearned advantaging for people gendered as men and unearned disadvantaging of people gendered as women (Burke \& Major, 2014; Cimpian, 2018; Leopold, et al., 2016); it is through this lens that the current study was designed and analyzed.

Given the stubborn pervasiveness of gender discrimination globally and the economic and social costs at stake, as well as the central role that men play, it is vital to explore what men can do to interrupt gender inequities (de Vries, 2015; UNWomen, 2018; Van Deven, 2009; Wagner, Yates, \& Walcott, 2012). Moreover, understanding what promotes men's effective gender equity efforts in higher education settings may be particularly beneficial since men faculty and administrators continue to hold an unrepresentative majority of higher education roles and are present in both the college classroom and the academic workplace. To that end, in this case study we begin by briefly considering current social contexts in regard to gender inequities, then discuss the theoretical frameworks and evolution of the Advocates \& Allies 
(A\&A) Program, a men faculty gender equity advocacy program. After describing the A\&A program in more detail, program evaluation data gathered over the past decade is summarized and interpreted.

In order to better understand and support academic men's motivations toward gender equity and to determine if/how the A\&A Program accords with effective allyship practices demonstrated in other contexts(Price, 2011; Reason, Broido, Davis, \& Evans, 2005; Sensoy \& DiAngelo, 2017a, 2017b; Stevens, 2010), this study is guided by the following two research questions: (RQ1) What draws men faculty to engage in gender equity efforts?; and (RQ2) Do the Ally Workshops successfully address the essential components of effective allyship?

Investigating these research questions will provide guidance for continuing to improve program effectiveness and, hopefully, will encourage a wider application of the A\&A Program within other academic and workplace settings.

Because the design of the A\&A Program as well as the current study addresses the gender equity role of people who identify as or are perceived as men, we continue to use the abbreviated woman/man binary. As will be described more fully in the section detailing the A\&A Program, the foundational and dynamic content of A\&A programming includes intersectional analyses and does not rely on this truncated version of gendering.

\section{Gender Inequities in Current Contexts}

Gender inequities in education have been observed as early as kindergarten (Cimpian, 2018), and there is growing acknowledgement that gendered discrimination is grounded in an assumed hierarchical gender binary of man/woman in which masculine norms are prized and feminine characteristics are viewed as inferior and often derogated (Bem, 1995; Bilimoria \& Stewart, 2009; BrckaLorenz, Garvey, Hurtado, \& Latopolski, 2017; Goldberg, Kuvalanka, \& 
dickey, 2018). Discriminatory practices in general result in a less effective workforce (Pilling, 2013; Polonski, 2017; Settles, Cortina, Malley, \& Stewart, 2006) and, because biased beliefs about gender are central to many forms of discrimination, workplace costs associated with gender-based discrimination are multiplicative.

Indeed, there are numerous studies that document the deleterious effects of gender disparities on women (e.g., Acker, 2012; Allen, 2017; Skewes et al., 2018; Stamarski \& Son Hing, 2015). For example, women may feel a sense of isolation, may not receive equal pay, may experience discrimination when seeking leadership positions and applying for promotions, or may decide to leave the institution. Critical theory suggests that in order to fully address any form of social inequity, individuals who are viewed as beneficiaries of a social status must understand the status quo as problematic and must work to change policies and practices that create and sustain discrimination (Guess, 1981). In terms of gender, such beneficiaries are typically heterosexual, cisgender men.

\section{Theoretical Frameworks: A Complex Critical Analysis}

The theoretical framework that informs the Advocates \& Allies Program blends complexity thinking with a critical analysis of gendered norms. Complexity thinking views social systems as complex and adaptive, meaning that multiple and diverse agents are connected and interdependent; as individuals and as groups, we learn and thus take novel, rather than predictable, action (Miller \& Page, 2007). Collective impact, understood as a "more effective process for social change" (Kania \& Kramer, 2013, p. 1) is grounded in complexity thinking; planning for and attending to the emergence of novel solutions is a central tenet.

A complexity accounting recognizes that local (micro), regional (meso) and global (macro) expressions of sociopolitical power share interconnected influence, and this analysis 
links directly to investigations of cultural beliefs and practices that either legitimate or disrupt inequities (Alexander \& Mohanty, 2010; Schneider \& Somers, 2006). Thus, a complex critical

analysis is one in which both individual and institutional factors are understood to generate environments that are either welcoming or unwelcoming for persons deemed atypical from the dominant majority (Page, 2011, 2012). Even while cultural and individual intentions explicitly esteem nondiscrimination, inequities persist. How is it that discriminatory beliefs and behaviors endure? The critical construct of hegemony, defined as harmful social power exerted by dominant groups via social, cultural, ideological, or economic pathways (Adamson, 1980; Figueroa, 2010; Gould, 2000; Lash, 2007) mirrors a complexity perspective and offers explanatory power for understanding the persistence of social inequities.

The complex critical framework that undergirds the A\&A Program directs explicit recognition of the harms of a gendered hierarchy for both men and women while simultaneously highlighting the benefits inherent in inclusive/diverse groups (Dailey-Hebert \& Dennis, 2015; Kania \& Kramer, 2013; Radford, 2008; Semetsky, 2008). This analysis reveals that men benefit from cultural and institutional changes that benefit women (J. L. Smith et al., 2017), and thereby provides a compelling path forward for addressing gender inequities.

\section{The Structures and Functions of Socialization}

Existing research suggests that gender differences across social sectors are primarily an outcome of socialization rather than biology and that gender-based discrimination in academia manifests in perceptions of women faculty as less competent, hirable, and promotable than men faculty(Johnson, 2017). Conceivably, men's socialization in gender superiority is causal (Kimmel, 2012), or it may be that gender-outsiders in arenas traditionally populated by men are perceived to "pollute" the profession (Goldin, 2014), or perhaps implicit biases and unconscious 
beliefs (Greenwald \& Krieger, 2006) drive discriminatory behaviors. It may also be that men question their psychological standing regarding gender equity advocacy, that is, the extent to which it is legitimate and right for them personally to participate in gender equity efforts. A series of correlational and experimental studies undertaken by Sherf, Tangirala, and Weber (2017) showed that in addition to other pragmatic or social considerations, men's beliefs about their psychological standing influences participation in gender equity initiatives.

Even though many men may want to work for gender equity (Barker, et al., 2010; Iyer \& Ryan, 2009; Wagner, et al., 2012), men engage in gender discrimination more frequently than women in three fundamental categories: unconscious bias/microaggressions, hostile or benevolent sexism/gender prejudice, and outright sexual harassment (K. Smith \& Gayles, 2018). As noted, there is a growing corpus of scholarship on the impacts of gender-based discrimination on women; however, little is known regarding why men engage in gender equity efforts and what approaches might support and encourage them to become allies for gender equity. Before delving into the specifics of the A\&A Program, we engage in a condensed review of the concept of allyship.

\section{Allyship: A Verb}

Allyship, which occurs when "members of dominant social groups (e.g., men, whites, heterosexuals) [work] to end the system of oppression that gives them greater privilege and power based on their social-group membership" (Reason \& Davis, 2005, p. 7), offers men a model for responding to gender inequity. Grounded in critical theory, meaningful allyship focuses on how social power is wielded, who benefits, and how social power can be employed for justice (Burghardt, 2011; Guess, 1981; Sleeter, 2010). Key understandings and behaviors 
have been identified for allies (Curry-Stevens, 2007; Ford, 2012; Tatum, 2017): allies need issuespecific knowledge, suitable tools, and sustained motivation.

Potential allies initially must learn how unearned advantaging/privilege works in their own lives and how that advantaging creates and perpetuates specific systemic disadvantaging of persons identified as "other." People who want to enter into allyship then need to obtain biasinterruption skills and tools. They must pursue opportunities to take action while holding themselves accountable to seek ongoing guidance and feedback from non-dominant group members. Successful ally development approaches must also educate, inspire, and support members of the dominant group in order to sustain the motivation required for the ongoing and often personally challenging project of cultivating a repertoire of ally behaviors (Reason \& Davis, 2005). As McKenzie (2014) articulates, acting as an ally is “...not an identity. It's a practice. It's an active thing that must be done over and over again, in the largest and smallest ways, every day" (p. 159). Allyship is most meaningfully understood as a verb rather than as a noun; allyship is iteratively (re)enacted.

Perceived barriers to men's involvement in gender equity work mirror difficulties described by advantaged groups regarding other forms of allyship (A. Bishop, 2002). Challenges reported by men in professional/corporate settings include lack of awareness/apathy, fear of backlash or status loss (i.e., male privilege), lack of specific knowledge about gender inequities, and unfamiliarity with strategies or skills that promote gender equity (Burke \& Major, 2014; Prime, Foust-Cummings, Salib, \& Moss-Racusin, 2012; Prime \& Moss-Racusin, 2009). Factors that promote men's engagement in gender equity work include increased awareness about unconscious bias and gender inequities, the development of a personal motivation for “championing" gender equity efforts, the presence of men role models, opportunities for men- 
only dialogues, and engagement in solution-building (Prime \& Moss-Racusin, 2009; Prime, Otterman, \& Salib, 2014). Additionally, men are more likely to engage in gender equity work when that is recognized as a legitimate role for them (Sherf, Tangirala, \& Weber, 2017).

\section{The History, Goals, and Structure of the Advocates \& Allies Program}

In 2008, a midwestern land grant university, as part of a larger set of activities to transform its gendered institution, originated the Advocates \& Allies (A\&A) Program. In order to engage men faculty members in gender equity work, the A\&A Program was developed as one unique module within a larger National Science Foundation funded ADVANCE Institutional Transformation project. The Advocates \& Allies program encourages both awareness and advocacy for transformative changes in faculty processes and relations. Specifically, the goals of the campus-wide A\&A Program are to: (1) educate men faculty about gender inequity in academia; (2) introduce men faculty to strategies for bringing about positive change in their departments and colleges; and (3) build a supportive network of men working to create a more equitable climate for women faculty and benefiting the entire campus see (Figure $1 \mathrm{~A}$ Schematic of the Advocates and Allies Program).

The A\&A Program evolved at a public university that had previously engaged in antiracism and anti-heteronormative activism (Anicha, Bilen-Green, \& Burnett, 2018). Two distinct groups comprise the programming aspects of the A\&A program: Advocates and Allies. The A\&A Program provides structured pathways to effectively engage men to promote gender equity and has been introduced at over twenty academic institutions nationwide.

Advocates are men faculty with a strong commitment and interest in supporting women faculty in their departments, colleges, and the university. Advocates are active proponents of gender equity and parity, specifically in terms of increasing the number of women faculty, 
encouraging the hiring and promotion of women faculty into administrative positions, and ensuring the fair and equitable treatment of women within their institution. They collaborate with academic women to increase their understanding of gender privilege and the impacts of gender bias on the academic careers of women.

Campus Advocate cohorts engage in ongoing self-education regarding intersectional manifestations of gendered advantaging and disadvantaging and update their knowledge bases regarding local and national statistics. Most importantly, the Advocates regularly offer Ally Workshops that are geared at increasing awareness of gender inequity for men faculty who are interested in becoming Allies. They also hold informal follow-up meetings to discuss case studies with the intent of continuing to increase their and Allies' knowledge about gender inequity in higher education.

Advocates meet regularly as part of their own ongoing education and to coordinate trainings for the Allies. The first group of Advocates who were instrumental in the development of the Advocates \& Allies Program spent over a year undergoing extensive training and preparing their own training curriculum for future advocates and allies. They read and discussed materials about unconscious bias and gender bias, and attended numerous gender equity and climate workshops and presentations by scholars including Virginia Valian, Joan Williams, Joey Sprague, Toni Schmader, and Mary Ann Mason. With the assistance of several facilitators from ADVANCE Institutions, including Mark Chester from the University of Michigan's STRIDE Program, they clarified their role as Advocates in the A\&A Program (Bilen-Green, Green, McGeorge, Anicha, \& Burnett, 2013).

Allies are men faculty who have attended a two-hour Ally Workshop, expressed commitment to furthering gender equity, and participated in informal follow-up meetings with 
Advocates and other allies. The Ally Workshops are structured to help men faculty understand basic aspects of male privilege and being an ally and to equip them with skills that will help them enhance their department climate and support their women colleagues (Anicha, Bilen-Green, Burnett, \& McGeorge, 2013; Bilen-Green, et al., 2013). Allies are expected to take action primarily within their departments, including: speaking up at meetings, inviting women colleagues to collaborate on research, asking women faculty about their research, and serving on committees in place of their women colleagues to reduce the inequity in service loads. Allies are invited to look to their campus Advocates for ongoing support and are encouraged to network with one another. They may volunteer to become Advocates as they become more familiar with the program.

Implementation of the A\&A Program at a new institution is facilitated by experienced Advocates who customize Ally Workshop materials with institution-specific equity and climate data and offer the Ally Workshops for faculty men. Once a group of workshop participants interested in becoming advocates is identified, experienced Advocates help facilitate formation of a new Advocates group by conducting group building exercises and the formation of a mission statement, group guidelines and structure, and an action list for the group (Bilen-Green et al., 2015). 

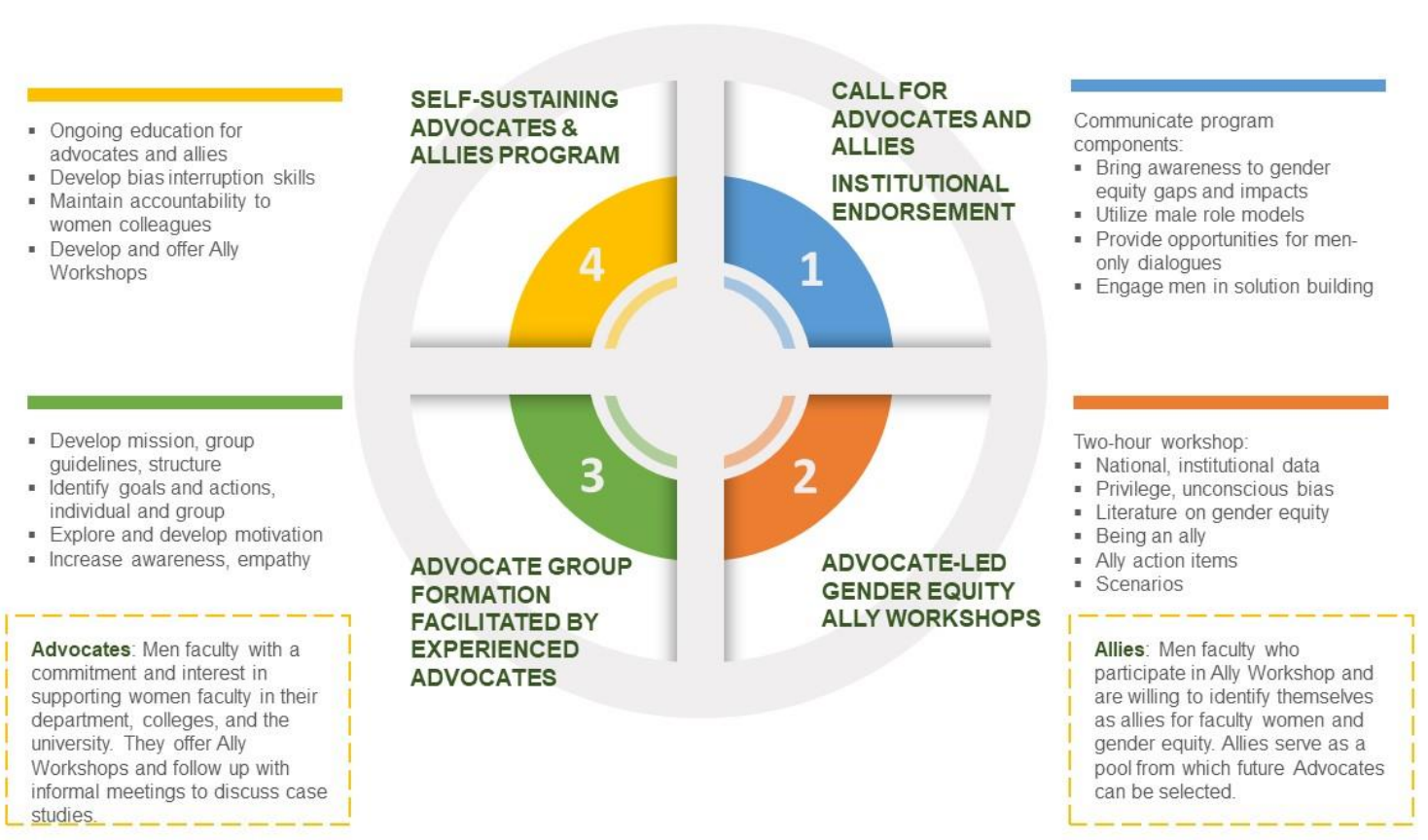

Figure 1. A Schematic of the Advocates and Allies Program

The A\&A Program is built on a strong foundation that includes a majority of elements found in successful profeminist gender equity anti-violence programs, while also incorporating several elements unique to academic settings (Anicha, Burnett, \& Bilen-Green, 2015).

Moreover, the A\&A Program appears to be related to improved retention and promotion of women faculty and the institutionalization of pro-diversity organizational structures and policies (Anicha, Bilen-Green, Burnett, Froelich, \& Holbrook, 2017). The A\&A Program is also wellgrounded in a community-based, and thus authoritative and trustworthy, vision of effective allyship that stresses both an intersectional analysis (Acker, 2012; A. Bishop, 2005; Crenshaw, 1991) and accountable collaboration with women faculty (Anicha, et al., 2018). The approach adheres to the above described elements of effective allyship while also directly addressing menspecific concerns by incorporating factors that promote men's engagement, then extends those precedents by undertaking allyship in the very specific contexts of higher education faculty. 
The peer-to-peer transformative pedagogy (Brookfield, 2005; McIntosh, 2012; Pohland \& Bova, 2000) central to A\&A includes: ongoing attention to self-reflection, engagement in continued learning within a network of peers, collaboration with women faculty, and clear expectations and opportunities for individual men and groups of men to work toward gender equity. The A\&A Program encourages academic men to establish self-sustaining gender equity networks that cross disciplines, ranks, and roles in order to foster a multilayered approach to undoing gender inequities.

Participants are prepared with the knowledge, tools, and motivation necessary for effective gender equity advocacy in academia. The complex critical framework and pedagogical approach employed by the A\&A Program is reflected in the purposes and expectations for transformative education. That is, equity-savvy faculty members wield immediate positive influence in the interpersonal realms of the workplace and classroom that supports faculty, staff, and student retention, which leads to the eventual development of a more equity-savvy campus community.

Data collected over the past decade have demonstrated the value of engaging men as advocates and allies for the advancement of women faculty. In 2015, an NSF Partnership for Learning and Adaptation Network (PLAN-D) award was received, to refine and evaluate the Advocates \& Allies Program in a variety of academic contexts, including: a large public university with an ADVANCE grant; a small, private, technological focused university that is post-ADVANCE grant; a southern mid-sized university without an ADVANCE grant; a western mid-sized university without an ADVANCE grant, and two professional membership associations. Although final measures of effectiveness-gender-parity in traditionally maledominated fields and consensus that a welcoming climate is well-established — may be decades 
away, the continuing engagement of men faculty across numerous academic settings supports a growing confidence in the A\&A Program.

\section{Methods}

Evaluation data collection includes individual interviews, pre-intervention surveys, and workshop participant formative questionnaires. Data from five institutions are the focus of the current study. Mixed methods (MM) research designs have been characterized as "the third methodological movement (paradigm)" following from quantitative as the first and qualitative as the second (Venkatesh, Brown, \& Bala, 2013, p. 22). MMs feature the integration of quantitative and qualitative approaches and are becoming increasingly sophisticated (Creswell, Klassen, Plano Clark, \& Smith, 2011; Schutt, 2017). The research questions identified for this study call for the flexible and meaningful integration of a variety of data sources offered through this methodology. Importantly, an MM design provides an especially effective avenue for understanding the "complex organizational and social phenomena" (Venkatesh et al., 2013, p. 22) reflected in this study's primary construct of interest - men faculty gender equity advocacy and allyship.

The method applied in this study combines several of the MM research design elements identified by Creswell (2014). In that the intent of the initiative is explicitly transformational (justice-oriented change), the element of Transformative design is present. A Sequential design element is suggested because selected data sets offer the opportunity to compare pre- and postmeasures of discrete constructs of interest (e.g., personal commitment to gender-equity work). Although most data are being collected over time as the Advocates \& Allies Program activities are completed, these data are not necessarily comparable in a chronological sense, essentially representing a Concurrent design element. The element of Triangulation is also present in that 
the qualitative and quantitative data have been analyzed separately and will be combined to broaden and strengthen the study findings (Creswell, 2014). Thus, the overall method, from research questions through to data collection, analyses, interpretations, and validation, follows a Sequential/Concurrent Triangulation Transformative research design.

Given the clear transformational and thus "openly ideological" (Lather, 1986) purposes of A\&A Program, and given that this Mixed Methods study included varied data sources, standards of data validity are briefly considered. With the exception of the ethnographic notes, the data used in this study are comprised of participant self-report. Although self-report is sometimes viewed with less confidence than other data forms, for the purposes of this investigation, personal experience and self-assessment of perceived learning were the objects of study; interviews and surveys provided the most direct and accessible path to that information.

The data sets analyzed here meet face validity in that the qualitative materials were directly related to either questions about involvement as a gender equity advocate (interviews) or were generated during Ally Workshops (ethnographic observations). Construct validity, the assertion that we have measured what we intended to measure, is claimed for the qualitative data based in expectations that interviewees provided truthful responses and that the ethnographers acted professionally in documenting their observations (see additional validity measures in Data Analysis section).

Regarding quantitative data sources, construct validity is claimed based on recognition that Likert-item formats meaningfully reflect personal views and opinions when responses are analyzed appropriately (P. A. Bishop \& Herron, 2015; Carifio \& Perla, 2007). Quantitative data for this study came from Likert-item questions on evaluation surveys and elicited responses from a broad majority of participants without requests for clarification. 
Standards of content validity (adequate coverage of the topic at hand) are effectively met by drawing on multiple sources of data reflecting previously established factors that influence men's engagement in gender equity efforts. Finally, external validity (generalizability) is deduced from the consistency of results found in this study from across varying organizational settings and a substantial participant data pool. Aggregate results are reported in the Results section.

\section{Participants}

Participants in this study included academic faculty and administrators who were interviewed (20 men), completed pre-intervention surveys (79 men) or completed a formative evaluation questionnaire at the conclusion of an Ally Workshop (213 men and 32 women). Of the twenty interviewees, 15 were Advocates from the originating university, and five were PLAN-D Advocate Coordinators responsible for overseeing the implementation of an A\&A Program on their campuses. The fifteen men faculty members from the originating university were in diverse disciplines, with experience in the A\&A Program ranging from two months to five years; all of the Advocate Coordinators were men faculty from engineering programs who were new to the A\&A Program.

Seventy-nine men faculty members and/or administrators from the four different PLAND institutions completed an online pretest prior to the initiation of an A\&A Program on their campuses. Following attendance at an Ally Workshop on those same four campuses, 150 men faculty and administrators completed a formative evaluation. In addition, 48 men faculty members and/or administrators completed formative evaluations following Ally Workshops presented at annual conferences of two professional engineering organizations. 
Finally, at the same annual conferences, 48 faculty completed formative evaluations following an Ally Workshop that was attended by both women and men (32 women, 15 men, and 1 person who did not provide their gender). It is important to note that on the formative evaluation questionnaires, beyond gender, no demographic data were gathered in order to ensure participants could not be identified and would provide truthful responses when evaluating the Ally Workshops.

\section{Data Collection}

Qualitative data were gathered to explore the first research question, (RQ1) What draws men faculty to engage in gender equity efforts? Data sources included one-on-one interviews completed by an external evaluator with men faculty Advocates at the originating university, interviews completed by an internal evaluator with PLAN-D Advocates, and ethnographic field notes collected by trained outside observers during Ally Workshops. All interviews were transcribed verbatim from digital recordings. All the qualitative data was de-identified prior to analysis.

For the purpose of the current study, researchers identified comments made by Advocates and workshop attendees regarding their participation in gender equity efforts. Interviews with the originating university Advocates took place in the third year following the inception of the initiative. Researchers identified comments these Advocates made regarding why they decided to join the group, resulting in 16 pages of single-spaced text. The Advocate Coordinators of the PLAN-D grant were each interviewed twice: once, before the program was initiated at their institution and second, about $1 \frac{1 / 2}{2}$ years after the program was initiated. The interview questions were slightly altered to reflect the progression of the program; however, in both interviews, the participants talked about their motivations for becoming Advocate Coordinators. Researchers 
pulled those comments from the eight interviews, which resulted in six pages of single-spaced text.

Four men (one at each of the four PLAN-D institutions) who were trained as ethnographic notetakers attended the Ally Workshops and created a record of responses, observations, and comments by workshop attendees. In particular, those notes included summaries or quotations from participant conversations, as well as observations about the atmosphere of the trainings and attendees' reactions to the training materials. Statements reflecting why men faculty desired to be Advocates were pulled from those notes, resulting in two pages of single-spaced text.

Quantitative data from pre-intervention surveys and post-Ally Workshop formative evaluation questionnaires were assembled to investigate the second research question, (RQ2) Do the Ally Workshops successfully address the essential components of effective allyship? The survey and evaluation instruments were designed to assess gains in participant learning and commitment to action, as well as to provide actionable formative data. In order to determine if participants acquired the essential components of effective allyship_issue-specific knowledge, suitable tools, and sustained motivation in support of gender equity - three response items from the survey/evaluation questionnaires (SQs) were selected.

Gains in specific knowledge were assessed by (SQ1) "I feel my knowledge of unconscious gender bias and its impact on the campus climate has increased after today's [Ally] Workshop", and acquisition of gender equity tools was assessed by (SQ2) "I will be able to implement new strategies to promote a more equitable climate for women faculty at my institution as a result of my participation in this [Ally] Workshop." 
Participant responses to (SQ3) "I am personally committed to addressing issues of gender bias and discrimination experienced by women faculty at my institution" obtained from preintervention surveys and post-workshop questionnaires were collected in order to assess changes in motivation for/commitment to gender equity work. The pre-intervention surveys showed a response rate of $78.2 \%$ and were administered campus-wide to men faculty and administrators who had registered for the initial Ally Workshop at the four PLAN-D institutions.

\section{Data Analysis}

To analyze the qualitative data, one of the authors read each transcript two times to get a comprehensive and immersive sense of the data. Next, each statement that reflected a reason for becoming an Advocate was highlighted and coded with an appropriate label. If a given response did not fit the existing categories, a new response category was created. This process resulted in 12 categories that were then consolidated in order to allow for more meaningful explanations of the data, similar to Pettus' (1990) method. To check for inter-rater reliability, an independent coder was trained to code about $10 \%$ of the data, then a Cohen's Kappa measure was administered, resulting in .71 agreement, which is substantial. Eight categories emerged that help elucidate why men faculty are motivated to become Advocates or Allies (see Table 1 Reasons for Becoming an Advocate).

Quantitative data for this study came from Likert-item queries on formative evaluation questionnaires offering six response categories (Strongly Disagree, Disagree, Somewhat Disagree, Somewhat Agree, Agree, and Strongly Agree). To analyze the quantitative data, the researchers compiled the PLAN-D universities' aggregate results from post- Ally Workshop formative evaluations and ran frequencies to assess learning in regard to knowledge of gender bias and its impacts on the acquisition of strategies for promoting gender equity. Data from the 
pre-intervention surveys were compared to post- Ally Workshop evaluations using frequencies to determine if personal commitment to gender equity was strengthened following workshop participation. Data comparisons reflect a generalized outcome rather than a measure of personal change.

\section{Results}

As a reminder, the first research question (RQ1) was, "What draws men faculty to engage in gender equity efforts?" The qualitative data gathered related to this question from A\&A participants could be organized into eight reasons as to why they were motivated to become Advocates and/or Allies. Motivation categories reflected personal or "internal" promptings for engaging in gender equity, with the exception of one "external" category that reflected prompting from other persons (e.g., administrators, other faculty). Nearly $1 / 3$ of the responses were in the See a Need category, in which the men faculty listed a variety of needs on their campuses. For example, one Advocate remarked, "When you go to our engineering college, which has struggled horrendously with gender representation, particularly at the faculty level. Yeah there's problems and anybody sees it." A second category was Example of a WrongDoing, illustrated by another Advocate who discussed a search process in his department in which a woman candidate was on the short list. The Advocate said,

I remember a couple of my senior colleagues saying, 'Well, looks like maybe she's been riding people's coattails.' And you look at her record, and she had something like 50 publications and it was 35 first author publications. Like, how can you look at that and say that she's been riding coat tails?

A third category of reasons Advocates provided for participating, Commitment to/Knowledge about Social Justice, was reflected in an ethnographic note, "Participants 
highlight[ed] their commitment to diversity and gender equity/empowerment." Wanting to Help, a fourth category, was expressed by an Advocate who noted that he had witnessed bias against women faculty in his "male-dominated" department, then stated, "I'd like to take steps to improve that and help more people understand the situation." Some Advocates were striving for Education/Self-Improvement, representing a fifth category, as reflected in this ethnographic note: Participants remarked that they "“just want to learn' or that they have seen some issues” (vague, not detailed).

Table 1. Reasons for Becoming an Advocate. Based on responses of advocates and allies from the originating institution and PLAN-D institutions to RQ1: What draws men faculty to engage in gender equity efforts?

\begin{tabular}{|c|c|c|}
\hline$\underline{\text { Motivation }}$ & $\frac{\stackrel{\# \text { of }}{\text { thought }}}{\underline{\text { units }}}$ & $\underline{\text { Example/Definition }}$ \\
\hline See a Need & 40 & $\begin{array}{l}\text { General comments about few female faculty, few female students, few } \\
\text { women in leadership, an "old boys" network, etc. }\end{array}$ \\
\hline $\begin{array}{l}\text { Example of a } \\
\text { Wrong-Doing }\end{array}$ & 16 & $\begin{array}{l}\text { Specific examples such as a colleague who made an inappropriate remark } \\
\text { in a meeting, an idea credited to a male faculty member that a female } \\
\text { faculty member presented, a female faculty member stuck at the } \\
\text { associate professor level, etc. }\end{array}$ \\
\hline $\begin{array}{l}\text { Commitment to/ } \\
\text { Knowledge about } \\
\text { Social Justice }\end{array}$ & 15 & $\begin{array}{l}\text { Commitment to gender equity or diversity; or knowledge about social } \\
\text { justice through previous workshops or through participant's own } \\
\text { research/work }\end{array}$ \\
\hline Want to Help & 12 & Desire expressed to be a change agent \\
\hline $\begin{array}{l}\text { Education/Self- } \\
\text { Improvement }\end{array}$ & 12 & Desire to learn more, to not be part of the problem \\
\hline $\begin{array}{l}\text { Female Family } \\
\text { Member }\end{array}$ & 9 & $\begin{array}{l}\text { Wife, daughter, or sister either in STEM or hopes for more equality in } \\
\text { the future for women }\end{array}$ \\
\hline $\begin{array}{l}\text { Influence/ } \\
\text { Experience }\end{array}$ & 6 & Belief in ability to influence change due to status or level of experience \\
\hline $\begin{array}{l}\text { Invitation/ } \\
\text { Nomination/ } \\
\text { Prodding }\end{array}$ & 6 & Advocate asked to attend training via invitation, nomination, or prodding \\
\hline Total & 116 & \\
\hline
\end{tabular}


A sixth response category revolved around Female Family Members, as reflected in this statement by an advocate: "Because, you know, I have two sisters. So I know the difficulty, they talk at home." A few of the participants felt they had Influence/Experience to make change, which was a seventh category, including one Advocate who was a department chair who said, "I also thought that our department was a good example, and I could lead from that because we went from a department of two women and eleven men to now being seven women and six men, and I'd like to think I had something to do with that.'Finally, men faculty wanted to be involved with the Advocates \& Allies Program due to Invitation/Nomination/Prodding. For example, Advocates shared that the provost or chair invited or nominated several of the men, and women faculty involved in the project had "prodded" two of them.

In terms of the second research question (RQ2), Do the and Ally Workshops successfully address the essential components of effective allyship?, we assessed the degree to which Ally Workshops yielded the intended results of increasing participants' perceived knowledge regarding key allyship skills. Specifically, two items were selected from post-workshop formative evaluations: (SQ1)“I feel my knowledge of unconscious gender bias and its impact on the campus climate has increased after today's workshop," and (SQ2) "I will be able to implement new strategies to promote a more equitable climate for women faculty at my institution as a result of my participation in this workshop" (see Figure 2 for campus Ally Workshops and Figure 3 for conference workshops). 


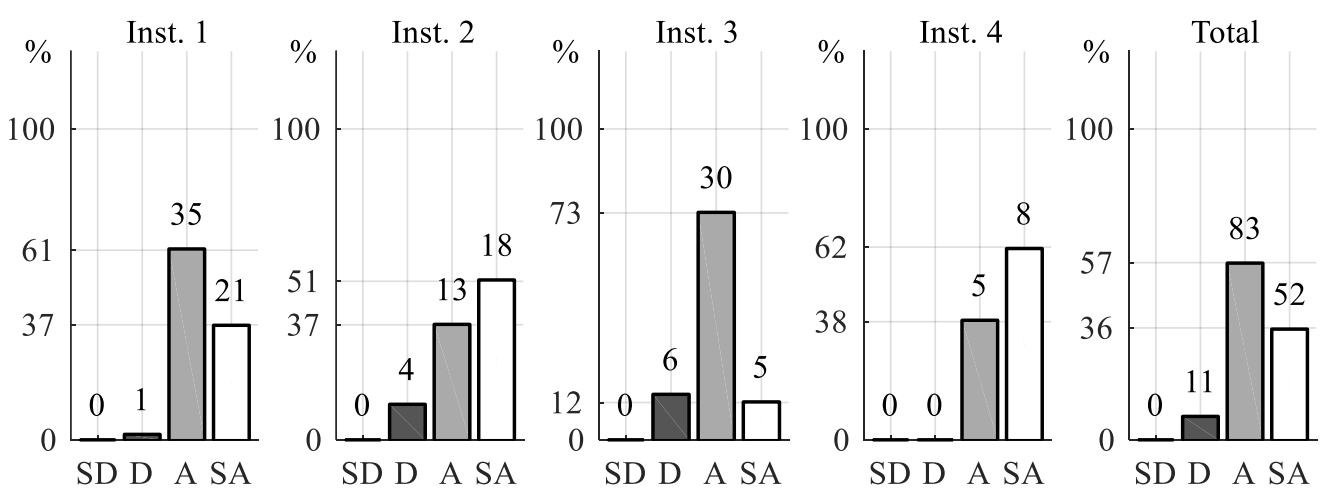

Figure 2.Ally Workshop Survey Question 1 (SQ1), Increased My Knowledge of Unconscious Gender Bias. Percentage and number of participant responses on Likert- item (SD-Strongly Disagree, D-Disagree, A-Agree, SA-Strongly Agree). Subplots 1-4 correspond to a different PLAN-D institution. Subplot titles (Inst. \#) include number (\#) of participants, not all of whom answered SQ1.

A majority $(92.47 \%)$ of participants either agreed or strongly agreed that their knowledge of unconscious bias and its impact on campus increased due to the training.

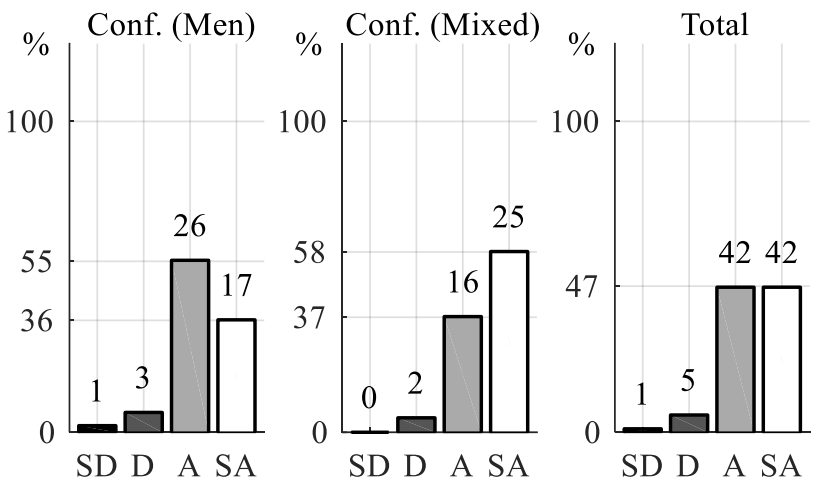

Figure 3.Ally Workshop Survey Question 1 (SQ1) for annual professional conferences Increased My Knowledge of Unconscious Gender Bias Percentage and number of participant responses on Likert-item (SD-Strongly Disagree, D-Disagree, A-Agree, SA-Strongly Agree). First subplot corresponds to men-only sessions and second subplot corresponds to mixed-gender sessions.

Similarly, a majority (84.03\%) of participants agreed or strongly agreed that they would be able to implement new strategies to promote a more equitable climate on their campuses (see Figure 4). 


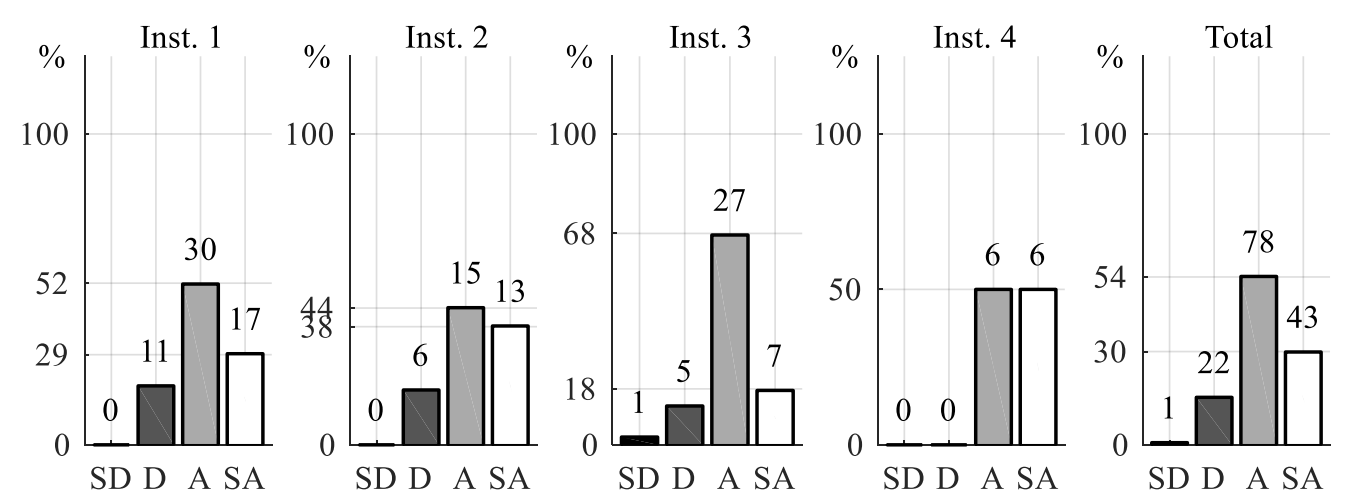

Figure 4.Ally Workshop Survey Question 2 (SQ2), Able to Implement New Strategies. Percentage and number of participant responses on Likert-item (SD-Strongly Disagree, DDisagree, A-Agree, SA-Strongly Agree). Subplots 1-4 correspond to a different PLAN-D institution. Subplot titles (Inst. \#) include number (\#) of participants, not all of whom answered SQ2.

With regard to Ally Workshops conducted at the annual professional conferences, response data reflect even stronger (93.33\% and 96.43\%, respectively) results (see Figure 5).

Motivation and commitment are key influences for men's engagement in gender equity work. On pre-surveys completed at the four PLAN-D institutions, 59\% of respondents indicated that they "Strongly Agree" with the statement (SQ3), "I am personally committed to addressing issues of gender bias and discrimination experienced by women faculty at my institution."

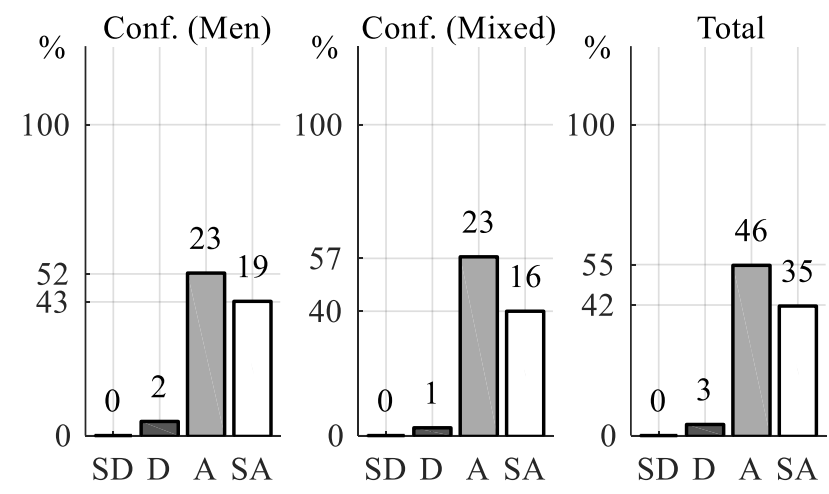

Figure 5.Ally Workshop Survey Question 2 (SQ2) for annual professional conferences Able to Implement New Strategies. Percentage and number of participant responses on Likert-item (SD-Strongly Disagree, D-Disagree, A-Agree, SA-Strongly Agree). First subplot corresponds to men-only sessions and second subplot corresponds to mixed-gender sessions. 
Comparisons of pre- and post-survey responses showed an average increase of 23 (range of 16-27) percentage points with $82 \%$ (range of 77-87) of participants selecting "Strongly Agree" in response to that statement following an Ally Workshop (See Figure 6).
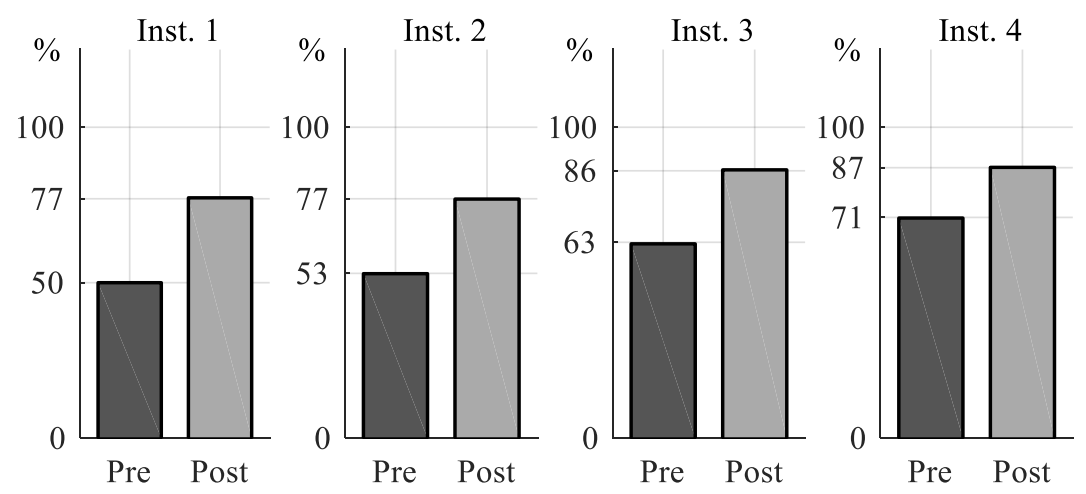

Figure 6. Percent of pre- and post-Ally Workshop participants who Strongly Agree to SQ3, Personally Committed to Gender Equity, by PLAN-D institution.

\section{Discussion}

The first research question asked (RQ1), What draws men faculty to engage in gender equity efforts? Analyses of the qualitative data reveal eight reasons for participation, seven of which were internal motivations, including knowledge that inequities existed, examples of inequities that were bothersome, and simply a desire to be part of the solution. It appears that initial awareness of gender inequity challenges, whether observed in the institution or described by women family members, may lead to a desire to learn more or to help. One external motivation, an invitation from an administrator or woman colleague, was enough to attract several men faculty to the Ally Workshops, but these men may have previously demonstrated some level of awareness in order to be "prodded" with such an invitation.

In the context of a social system in which norms for men dictate rigid boundaries of what a man "should" be (Kimmel \& Messner, 2012), these data suggest when men faculty are offered 
an opportunity to veer away from those norms and to fight for gender equity, they are willing to do so. However, participating in gender equity efforts is not without cost for men allies who may experience a loss of social status and power. The A\&A components of using men role models as workshop leaders and ensuring men-only dialogue may be the keys to breaking masculine gender norms in this context. Moreover, men faculty gender equity advocates may need both internal (group) and external (administration, women faculty) support. Given the dogged persistence of gendered inequities in higher education, men's gender equity advocacy coming from administrative sources as well as from faculty colleagues may be critical to supporting effective gender equity allyship in men faculty.

The second research question asked (RQ2), Do the Ally Workshops successfully address the essential components of effective allyship? Based on the three key items pulled from the post-Ally Workshop formative evaluations, participants reported the training effectively increased their awareness of gender inequities, provided them with usable strategies and tools to apply in their own contexts, and positively influenced their commitment to work for gender equity. Open-ended participant comments indicated that a few participants expressed disagreement with one or both of these items; in those cases, the respondent either felt the need for additional time to absorb what was for them new information, or, had been active in genderequity work already and wished to spend less time on describing the problem and more time on developing actionable solutions. The overwhelming positive feedback on the 22 Ally Workshops assessed for this study suggests that the A\&A theoretical frameworks and pedagogical approach are effective change agent tools.

In particular, the items from the formative evaluation surveys, increasing awareness of unconscious bias, perceived ability to enact change, and commitment to engage in gender equity 
work, represent important tools for combating the powerful presence gender inequities, especially in STEM departments. Awareness and knowledge of gender inequities can expose behaviors such as interrupting women at meetings or considering women only as teachers and not as researchers. With strategies and motivation to change those behaviors, men faculty may play an effective role in changing campus climate. Also of note, these components mirror components identified in other workplace venues as supporting men's engagement in gender equity, increasing awareness of gender bias and engagement of solution building(Burke and Major, 2014; Prime \& Moss-Racusin, 2009), underscoring key aspects of the A\&A Program.

The implementation of A\&A Program at the originating institution as well as other institutions underscore the importance of helping advocates and allies develop and sustain their knowledge, vocabulary, awareness, and skill. Faculty men (and women) need time to develop expertise and comfort in publicly engaging others in gender equity issues. Additional training and preparation may be needed at non-ADVANCE Institutions. As any new change initiative, endorsement and support of top university administrators is also critical to build interest in the program. Collaborations with women colleagues and existing faculty development and climate programs can help A\&A groups identify areas of need and enhance impact of their efforts. Clear and attainable goals, such as offering Ally Workshops, improving a policy, or nominating women colleagues for awards, can help focus efforts, build cohesion, promote purpose and accountability, and provide a platform for growth of advocates (Bilen-Green, et al., 2015).

The creation of the A \& A program at multiple institutions is occurring at an important time. International attention to men's roles in gender justice is growing (Barker, et al., 2010). Some speculate this is due to the realization that workplace inequalities negatively impact the productivity and the financial bottom lines of U.S. corporations and non-profits, and as such 
practices for fostering racial and gender justice have received renewed attention (Prime, FoustCummings, Salib, \& Moss-Racusin, 2012; Prime \& Moss-Racusin, 2009). The presence of online gender equity advocacy organizations may also testify to the perceived need and/or effectiveness of men as gender justice allies (see for example, Men Advocating Real Change (MARC; http://onthemarc.org/home). Principles of allyship appear to be helpful in addressing gender inequities in higher education.

From a methodological perspective, the Mixed Methods approach taken in this study has provided a useful way to investigate the research questions that derive from the explicitly transformational (justice-oriented) change intended by A\&A. By examining data from ethnographic field notes, individual interviews, and pre- and post-Ally Workshop surveys from a variety of institutions, data sources were available to triangulate, and thus to cross-validate, the findings. Multiple data points offered a variety of avenues to discover the impact of the program, and these data were effectively combined to broaden and strengthen study findings. Therefore, a MM research design offered a new way to examine the functions of allyship in general, and men's gender equity advocacy and allyship in particular.

As with any research project, this study has its limitations. The application of a binary gender demographic is incomplete from an intersectional perspective. However, as we have articulated, the over-advantaging of people who identify as, or are perceived as, men is a crucial distinction when seeking to address inequities from the position of those who are overadvantaged. Further, the PLAN-D project is not yet complete; therefore, project personnel await evaluation data that will provide additional information about the effectiveness of the A\&A Program in promoting meaningful and measurable institutional transformation. Finally, one of the final evaluation steps with the PLAN-D grant is to conduct focus groups of women faculty 
whose perspectives will be valuable to understanding the way A\&A operated on those campuses. Despite these limitations, we offer convincing evidence that A\&A is worthy of future research and implementation.

\section{Conclusions}

The qualitative data analyzed for this study offers meaningful insights regarding what draws men faculty to engage with a program explicitly designed to improve the recruitment, retention, and advancement of women faculty. Implementation of the A\&A Program at an institution is likely to affirm to faculty men that they have the psychological standing to actively engage in gender equity initiatives. Moreover, quantitative findings demonstrated that participants in Ally Workshops overwhelmingly agree that they came away with increased levels of knowledge regarding gendered inequities and an improved set of skills for building gender equity. Perhaps most pointedly, respondents' personal commitment to working for gender equity appears to have been substantively strengthened. The A\&A Program has the potential to improve the chilly climate for women faculty by pushing back on toxic gender norms via networks of allied men faculty. By also integrating key elements of social justice allyship training with elements identified by men as being especially supportive of their gender equity work, this innovative idea holds much promise. In order for all disciplines to fully thrive, opening the doors of welcome and opportunity to more women faculty (and students) is an important and consequential goal. 


\section{References}

Acker, J. (2012). Gendered organizations and intersectionality: Problems and possibilities. Equality, Diversity and Inclusion: An International Journal, 31(3), 214-224. doi: $10.1108 / 02610151211209072$

Adamson, W. L. (1980). Hegemony and revolution: A study of Antonio Gramsci's political and cultural theory. Berkeley, CA: University of California Press.

Alexander, M. J., \& Mohanty, C. T. (2010). Cartographies of Knowledge and Power: Transnational Feminism as Radical Praxis. In R. Nagar \& A. L. Swarr (Eds.), Critical Transnational Feminist Praxis (pp. 23-45). Albany, NY: State University of New York Press.

Allen, R. (2017, May 3). Gender Inequality in Medicine: Too Much Evidence to Ignore. Psychiatric Times, 34.

Anicha, C. L., Bilen-Green, C., \& Burnett, A. (2018). Advocates \& Allies: The Succession of a Good Idea Or What's in a Meme? [Dispatches]. Studies in Social Justice, 12(1), 152-164. doi: https://doi.org/10.26522/ssj.v12i1.1613

Anicha, C. L., Bilen-Green, C., Burnett, A., Froelich, K., \& Holbrook, S. (2017). Institutional Transformation: Toward a Diversity-Positive Campus Culture. Journal of Women and Minorities in Science and Engineering, 23(2). doi:

10.1615/JWomenMinorScienEng.2017017021

Anicha, C. L., Bilen-Green, C., Burnett, A., \& McGeorge, C. R. (2013). Activating Advocates and Allies for Gender Equity: Engaging with Male Colleagues. Paper presented at the Women in Engineering ProActive Network Annual Conference, Atlanta, GA. 
Anicha, C. L., Burnett, A., \& Bilen-Green, C. (2015). Men faculty gender-equity advocates: A qualitative analysis of theory and praxis. Journal of Men's Studies, 23(1), 21-43. doi: $10.1177 / 1060826514561974$

Barker, G., Greene, M. E., Goldstein-Siegel, E., Nascimento, M., Segundo, M., Ricardo, C., et al. (2010). What Men Have to Do With It: Public Policies to Promote Gender Equality. The Men and Gender Equality Policy Project. Retrieved from http://www.icrw.org/files/publications/What-Men-Have-to-Do-With-It.pdf

Bem, S. L. (1995). Dismantling gender polarization and compulsory heterosexuality: Should we turn the volume down or up? Journal of Sex Research, 32(4), 329-334.

Bilen-Green, C., Carpenter, J., Doore, S., Green, R. A., Horton, K., Jellison, K., et al. (2015). Implementation of Advocates and Allies Programs to Support and Promote Gender Equity in Academia. Paper presented at the Women in Engineering Division: Faculty and Gender Issues, Seattle, WA.

Bilen-Green, C., Green, R., McGeorge, C. R., Anicha, C. L., \& Burnett, A. (2013). Engaging Male Faculty in Institutional Transformation. Paper presented at the ASEE Annual Conference \& Exposition, Atlanta, GA.

Bilimoria, D., \& Stewart, A. J. (2009). "Don't ask, don't tell": The academic climate for lesbian, gay, bisexual, and transgender faculty in science and engineering. National Women's Studies Association Journal, 21(2), 85-103.

Bishop, A. (2002). Becoming an Ally: Breaking the Cycle of Oppression in People. Halifax, Nova Scotia: Fernwood.

Bishop, A. (2005). Beyond token change: Breaking the cycle of oppression in institutions. Halifax, N.S.: Fernwood. 
Bishop, P. A., \& Herron, R. L. (2015). Use and Misuse of the Likert Item Responses and Other Ordinal Measures. International Journal of Exercise Science, 8(3), 297-302.

BrckaLorenz, A., Garvey, J. C., Hurtado, S. S., \& Latopolski, K. (2017). High-impact practices and student-faculty interactions for gender-variant students. Journal of Diversity in Higher Education, 10(4), 350-365. doi: 10.1037/dhe0000065

Brookfield, S. (2005). The power of critical theory: Liberating adult learning and teaching (First ed.). San Francisco, CA: Jossey-Bass.

Burghardt, M. (2011). The Human Bottom of Non-Human Things: On Critical Theory and its contributions to Critical Disability Studies Critical Disability Discourse, 3, 1-16. Retrieved from https://pi.library.yorku.ca/ojs/index.php/cdd/article/view/31560

Burke, R. J., \& Major, D. A. (Eds.). (2014). Gender in organizations: Are men allies or adversaries to women's career advancement? Northampton, MA: Edward Elgar Publishing Limited.

Carifio, J., \& Perla, R. J. (2007). Ten Common Misunderstandings, Misconceptions, Persistent Myths and Urban Legends about Likert Scales and Likert Response Formats and their Antidotes. Journal of Social Sciences, 3(3), 106-116. doi: 10.3844/jssp.2007.106.116

Cimpian, J. (2018, July 2). How our education system undermines gender equity: And why culture change — not policy — may be the solution Retrieved from https://www.brookings.edu/blog/brown-center-chalkboard/2018/04/23/how-oureducation-system-undermines-gender-equity/

Crenshaw, K. (1991). Mapping the Margins: Intersectionality, Identity Politics, and Violence against Women of Color. Stanford Law Review, 43(6), 1241-1299. doi: 10.2307/1229039 
Creswell, J. (2014). Research design: Qualitative, quantitative, and mixed methods approaches (4th ed.). Los Angeles, CA: Sage.

Creswell, J., Klassen, A., Plano Clark, V., \& Smith, K. (2011). Best practices for mixed methods research in the health sciences Retrieved from https://obssr.od.nih.gov/training/onlinetraining-resources/mixed-methods-research/

Curry-Stevens, A. (2007). New Forms of Transformative Education: Pedagogy for the Privileged. Journal of Transformative Education, 5(1), 33-58. doi: $10.1177 / 1541344607299394$

Dailey-Hebert, A., \& Dennis, K. S. (Eds.). (2015). Transformative perspectives and processes in higher education. Switzerland: Springer International Publishing.

de Vries, J. (2015). Champions of gender equality: Female and male executives as leaders of gender change. Equality, Diversity and Inclusion: An International Journal, 34(1), 21-36. doi: https://doi.org/10.1108/EDI-05-2013-0031

Dockendorff, K. J., \& Geist, C. (2018). Gender trouble beyond the LGB and T: Gender Image and Experiences of Marginalization on Campus. SocArXiv Papers. Retrieved from doi: https://doi.org/10.31235/osf.io/kg6f2

Figueroa, F. E. (2010). The Bologna Process as a hegemonic tool of Normative Power Europe (NPE): The case of Chilean and Mexican higher education. Globalisation, Societies and Education, 8(2), 247-256. doi: 10.1080/14767721003779936

Ford, K. A. (2012). Shifting White Ideological Scripts: The Educational Benefits of Inter- and Intraracial Curricular Dialogues on the Experiences of White College Students. Journal of Diversity in Higher Education. doi: 10.1037/a0028917 
Goldberg, A. E., Kuvalanka, K., \& dickey, 1. (2018). Transgender graduate students' experiences in higher education: A mixed-methods exploratory study. Journal of Diversity in Higher Education. doi: 10.1037/dhe0000074

Goldin, C. (2014). A pollution theory of discrimination: Male and female differences in occupations and earnings. In L. P. Boustan, C. Frydman \& R. A. Margo. (Eds.), Human Capital Theory: The American Record (pp. 313-348). Chicago, IL: University of Chicago Press.

Gould, S. J. (2000). Deconstructing the "Science Wars" by Reconstructing an Old Mold. Science, 287(5451), 253-261. doi: 10.1126/science.287.5451.253

Greenwald, A. G., \& Krieger, L. H. (2006). Implicit Bias: Scientific Foundations. California Law Review, 94(4), 945-967.

Greider, C. W., Sheltzer, J. M., Cantalupo, N. C., Copeland, W. B., Dasgupta, N., Hopkins, N., et al. (2019). Increasing gender diversity in the STEM research workforce. Science, 366(6466), 692-695. doi: 10.1126/science.aaz0649

Guess, R. (1981). The idea of a critical theory: Habermas and the Frankfurt school. New York, NY: Press Syndicate of the Cambridge University Press.

Iyer, A., \& Ryan, M. K. (2009). Why Do Men and Women Challenge Gender Discrimination in the Workplace? The Role of Group Status and In-group Identification in Predicting Pathways to Collective Action. Journal of Social Issues, 65(4), 791-814. doi: $10.1111 / \mathrm{j} .1540-4560.2009 .01625 . \mathrm{x}$

Johnson, S. K. (2017). What the Science Actually Says About Gender Gaps in the Workplace. Harvard Business Review, (August 17). Retrieved from https://hbr.org/2017/08/what-thescience-actually-says-about-gender-gaps-in-the-workplace 
Kamrany, N. M., \& Robinson, C. (2012). The Global Problem of Gender Inequality. The Blog, 2018(August 9). Retrieved from https://www.huffpost.com/entry/genderinequality_b_1417535

Kania, J., \& Kramer, M. (2013). Embracing Emergence: How Collective Impact Addresses Complexity. Stanford Social Innovation Review, Collaboration(January 21), 7.

Kimmel, M. S. (2012). Manhood in America: A cultural history. New York, NY: Oxford University Press.

Kimmel, M. S., \& Messner, M. A. (2012). Men's lives. Boston, MA: Pearson.

Kivel, P. (1999). Boys Will Be Men: Raising Our Sons for Courage, Caring and Community. Gabriola Island, B.C. Canada:: New Society Publishers.

Lash, S. (2007). Power after Hegemony: Cultural Studies in Mutation? Theory Culture and Society, 24(3), 55-78. doi: 10.1177/0263276407075956

Lather, P. (1986). Issues of Validity in Openly Ideological Research: Between a Rock and a Soft Place. Interchange, 17(4), 63-84.

Leopold, T. A., Ratcheva, V., \& Zahidi, S. (2016). The Globale Gender Gap Report 2016: Insight Report (pp. 391). Geneva, Switzerland: World Economic Forum.

McIntosh, P. (2012). Reflections and Future Directions for Privilege Studies. Journal of Social Issues, 68(1), 194-206. doi: 10.1111/j.1540-4560.2011.01744.x

McKenzie, M. (2014). Black Girl Dangerous: On Race, Queerness, Class and Gender: Black Girl Dangerous Press.

Messerschmidt, J. W. (2012). Engendering Gendered Knowledge. Men and Masculinities, 15(1), 56-76. doi: $10.1177 / 1097184 \times 11428384$ 
Miller, J., \& Page, S. E. (2007). Complex Adaptive Systems: An Introduction to Computational Models of Social Life. Princeton, NJ: Princeton University Press.

Page, S. E. (2011). Diversity and Complexity. Princeton, NJ: Princeton University Press.

Page, S. E. (2012). The Hidden Factor: Why Thinking Differently Is Your Greatest Asset. Chantilly, VA: The Teaching Company.

Pettus, A. B. (1990). The verdict is in: A study of jury decision making factors, moment of personal decision, and jury deliberations - from the jurors' point of view. Communication Quarterly, 38(1), 83-97. doi: 10.1080/01463379009369743

Pilling, M. D. (2013). Invisible Identity in the Workplace: Intersectional Madness and Processes of Disclosure at Work Disability Studies Quarterly, 33(1). Retrieved from http://dsqsds.org/article/view/3424/3204

Pitcher, E. N. (2017). 'There's stuff that comes with being an unexpected guest': Experiences of trans* academics with microaggressions. International Journal of Qualitative Studies in Education, 30(7), 688-703. doi: 10.1080/09518398.2017.1309588

Pohland, P., \& Bova, B. (2000). Professional development as transformational learning. International Journal of Leadership in Education, 3(2), 137-150. doi: $10.1080 / 136031200292786$

Polonski, V. (2017). 5 things that must change to end gender inequality at work. World Economic Forum, Global Agenda(Gender Parity). Retrieved from https://www.weforum.org/agenda/2017/02/5-things-that-must-change-to-end-genderinequality-at-work/

Preves, S. E. (2005). Intersex and identity: The Contested Self. New Brunswick, NJ: Rutgers University Press. 
Price, M. (2011). Mad at School: Rhetorics of mental disability and academic life. Ann Arbor, MI: University of Michigan Press.

Prime, J., Foust-Cummings, H., Salib, E. R., \& Moss-Racusin, C. A. (2012). Calling All White Men!: Can Training Help Create Inclusive Workplaces? Research Reviews. Retrieved from http://www.catalyst.org/knowledge/calling-all-white-men-can-training-help-createinclusive-workplaces

Prime, J., \& Moss-Racusin, C. A. (2009). Engaging Men in Gender Initiatives: What Change Agents Need to Know. Research Reviews. Retrieved from http://www.catalyst.org/file/283/mdc-web.pdf

Prime, J., Otterman, M., \& Salib, E. R. (2014). Engaging men tough inclusive leadership. In R. J. Burke \& D. A. Major (Eds.), Gender in organizations: Are men allies or adversaries to women's career advancement? (pp. 385-404). Northampton, MA: Edward Elgar Publishing Limited.

Radford, M. (2008). Complexity and Truth in Educational Research. Educational Philosophy and Theory, 40(1), 144-157. doi: 10.1111/j.1469-5812.2007.00396.x

Reason, R. D., Broido, E. M., Davis, T. L., \& Evans, N. J. (Eds.). (2005). Developing social justice allies (Vol. 110). San Francisco, CA: Jossey-Bass.

Reason, R. D., \& Davis, T. L. (2005). Antecedents, precursors, and concurrent concepts in the development of social justice attitudes and actions. New Directions for Student Services, Summer(110), 5-15. doi: 10.1002/ss.161

Schneider, M., \& Somers, M. (2006). Organizations as complex adaptive systems: Implications of Complexity Theory for leadership research. The Leadership Quarterly, 17(4), 351-365. doi: 10.1016/j.leaqua.2006.04.006 
Schutt, R. K. (2017). Understanding the social world: Research methods for the 21 st century. Los Angeles, CA: SAGE.

Semetsky, I. (2008). On the Creative Logic of Education, or: Re-reading Dewey through the lens of complexity science. Educational Philosophy and Theory, 40(1), 83-95. doi: 10.1111/j.1469-5812.2007.00409.x

Sensoy, Ö., \& DiAngelo, R. (2017a). Is Everyone Really Equal?: An introduction to key concepts in social justice education (2nd ed.). New York, NY: Teachers College Press.

Sensoy, Ö., \& DiAngelo, R. (2017b). “We Are All for Diversity, but . ..”: How Faculty Hiring Committees Reproduce Whiteness and Practical Suggestions for How They Can Change. Harvard Educational Review, 87(4), 557-580. doi: 10.17763/1943-5045-87.4.557

Settles, I. H., Cortina, L. M., Malley, J., \& Stewart, A. J. (2006). The climate for women in academic science: The good, the bad, and the changeable. Psychology of Women Quarterly, 30, 47-58. doi: 10.1111/j.1471-6402.2006.00261.x

Sherf, E. N., Tangirala, S., \& Weber, K. C. (2017). It Is Not My Place! Psychological Standing and Men's Voice and Participation in Gender-Parity Initiatives. Organization Science, 28(2), 193-210. doi: 10.1287/orsc.2017.1118

Shields, S. A., \& Dicicco, E. C. (2011). The Social Psychology of Sex and Gender: From Gender Differences to Doing Gender. Psychology of Women Quarterly, 35(3), 491-499. doi: $10.1177 / 0361684311414823$

Skewes, M. C., Shanahan, E. A., Smith, J. L., Honea, J. C., Belou, R., Rushing, S., et al. (2018). Absent autonomy: Relational competence and gendered paths to faculty selfdetermination in the promotion and tenure process. Journal of Diversity in Higher Education, 11(3), 366-383. doi: 10.1037/dhe0000064 
Sleeter, C. (2010). Building Counter-Theory about Disability. Disability Studies Quarterly, 30(2). Retrieved from http://dsq-sds.org/article/view/1244/1288

Smith, J. L., Handley, I. M., Rushing, S., Belou, R., Shanahan, E. A., Skewes, M. C., et al. (2017). Added Benefits: How Supporting Women Faculty in STEM Improves Everyone's Job Satisfaction. Journal of Diversity in Higher Education. doi: $10.1037 /$ dhe0000066

Smith, K., \& Gayles, J. (2018). "Girl Power": Gendered Academic and Workplace Experiences of College Women in Engineering. Social Sciences, 7(1), 11. doi: https://doi.org/10.3390/socsci7010011

Stamarski, C. S., \& Son Hing, L. S. (2015). Gender inequalities in the workplace: the effects of organizational structures, processes, practices, and decision makers' sexism. Frontiers in Psychology, 6, 1400. doi: 10.3389/fpsyg.2015.01400

Stevens, B. (2010). Recognizing and Undoing Ableism. Education, National Youth Advocacy CoalitionWashington, DC [video]. YouTube.https://www.youtube.com/watch?v=FRLcbQF5iWE

Tatum, B. D. (2017). Why Are All The Black Kids Sitting Together in the Cafeteria?": And other conversations about race (20th Anniversary ed.). New York, NY: Basic Books.

UNWomen. (2018). The HeForShe campaign, 2018, from http://www.heforshe.org/en

Van Deven, M. (2009, Fall). Is Feminism Men's Work, Too? Herizons, 23, 16-21.

Venkatesh, V., Brown, S., \& Bala, H. (2013). Bridging the Qualitative-Quantitative Divide: Guidelines for Conducting Mixed Methods Research in Information Systems. Management Information Systems Quarterly, 37(1), 21-54. 
Wagner, K., Yates, D., \& Walcott, Q. (2012). Engaging men and women as allies: A workplace curriculum module to challenge gender norms about domestic violence, male bullying and workplace violence and encourage ally behavior. Work, 42(1), 107-113. doi: 10.3233/WOR-2012-1334

Wing, B. W. (2008). Degendering and Regendering: Recomposing Masculinities through AntiSexist Masculinity Projects. PhD, University of Missouri, Columbia.

Zamani-Gallaher, E. M., Choudhuri, D. D., \& Taylor, J. L. (2020). Rethinking LGBTQIA students and collegiate contexts : identity, policies, and campus climate. 